\title{
Overview on the Growth and Development of TikTok's Globalization
}

\author{
Xin $\mathrm{He}^{1, \dagger}$, Keyu $\mathrm{Hua}^{2, \dagger}$, Chen $\mathrm{Ji}^{3, \dagger}$, Haichuan $\operatorname{Lin}^{4, *},{ }^{*}$, Zhengqi Ren ${ }^{5, \dagger}$, Wenyu \\ Zhang ${ }^{6, \dagger}$
}

\author{
${ }^{1}$ Beijing Union University, Hunan, China \\ ${ }^{2}$ Shanghai Lixin University of Accounting and Finance, Shanghai, China \\ ${ }^{3}$ ChenJiHangzhou Business School of Zhejiang Gongshang University, ZheJiang Province, China \\ ${ }^{4}$ Business school, University of Sydney, Beijing, China \\ ${ }^{5}$ University of Miami, Tianjin, China \\ ${ }^{6}$ School of economics and management, Hebei University of Economics and Business, ShiJiaZhuang, China \\ "Corresponding author. Email: hlin4875@uni.sydney.edu.au \\ These authors contributed equally.
}

\begin{abstract}
After years of development, watching short videos have become a component of the general public. The objective of this study was to analyze TikTok business model, engage in its product internationalization and valuation, and investigate the potential risk TikTok may face. In terms of market share in China and overseas, TikTok owns a broader market prospect and has more advantages the One smile. This research focuses on the success of TikTok and its core competitiveness, and some potential risks. TikTok has taken steps to paint itself as an American brand even if the executive orders also underline what is at stake in the potential "decoupling" of the U.S. The success of chattering proves the vast market potential of the domestic short video platforms. At the same time, it also reflects the correctness and uniqueness of the business model.
\end{abstract}

Keywords: TikTok, competition advantage, globalization, regulation, potential risk

\section{INTRODUCTION}

In recent years, with the extensive use of social software, a more accessible and more efficient social environment allows people to fully express their discourse power and provides a more effective platform. According to the Statistical Survey of China's Internet Development released by China's Internet Information Survey Center in Beijing, at the beginning of 2019, China's Internet users exceeded 752 million, with a network coverage rate of $55.3 \%$, showing the considerable base of the Internet community in China. The continuous development of new media technology also provides additional robust support for users to express their opinion and information. According to statistics, Generation $\mathrm{Y}$ and $\mathrm{Z}$ have become the main force of short video viewing. These two generations constitute the primary consumption of short video. The personalized recommendation mechanism based on big data of the short video platform makes short videos more "intelligent" that can be recommended to the relevant users. Its emergence and development cater to the need of modern life, which has promoted some lifestyle changes.

Nowadays, creating economic growth through the Internet is workable. As one of the new forms of Internet economy, the internet celebrity economy has developed rapidly in recent years. Internet celebrity economy can be defined as basing on the Internet and gathering many social attentions, forming a substantial amount of fan and targeted marketing. The main ways to realize the internet celebrity economy include e-commerce, IP sale, contract reward, advertising, and entertainment. E-commerce is the most important way to realize the web celebrity economy. Since it emerged in 2013, it has developed rapidly for five years. According to the 2018 China web celebrity Economic Development Insights Report, as of May 2018, the total number of web celebrity fans in China reached 588 million, and $53.9 \%$ of them were under the age of 25 , which indicates that the Internet 
social APP users are generally younger. In addition, since 2018, the flow of short videos has led to another wave of development of the web celebrity economy. According to the 43rd Statistical Report on Internet Development in China released by the Internet Network Information Center (CNNIC), the number of short video users in China reached 648 million in December 2018. The dividends of mobile social networking continue to appear, and e-commerce based on social e-commerce has become one of the most active and promising models. Tiktok is social software for short videos of music creativity incubated by Toutiao. Launched on September 20,2016 , it is a social platform for short music videos for all ages. Users can choose songs, shoot short music videos and form their works through this software. In addition, users can update videos they preferred according to their browsing history. In December 2019, Tiktok selected as one of the 100 model brands in the 2019 China Brand Power Ceremony

\section{LITERATURE REVIEW}

$\mathrm{Su}$ et al. adopted a netnographic and comparative approach to explore the potential of TikTok as an emerging fan engagement and self-branding tool during a pandemic. Based on ten athletes, findings reveal that the traits of TikTok, playfulness, performativity and authenticity, are conducive to developing an engaged fan relationship, tapping into new audiences, and promoting the content of the brand in a more casual way [1]. Based on Uses and Gratifications theory, Omar and Dequan used online network sampling technique, rating scale of survey and controlled variables - Demographic factors to investigate people's usage involving consuming, participating and producing behaviors as well as the role of user's personality traits and motivations as predictors to this integrated usage behavior. The results show that different types of motivation influence media usage, while personality trade are not significantly related to any TikTok usage behaviors [2]. Mou does research on the marketing strategy of TikTok and Instagram. In order to achieve the goal, Mou investigates in co-creation and virtual community transformed consumers' interaction with one and another; compares consumers' different reactions to content marketing, and sponsored content together with user-generated content. She uses empathy interviews, case studies to understand how consumers behave to different social media marketing programs and made her recommendations to companies developing their social media marketing strategy. With insights obtained from literature review, case studies and consumer interviews, Mou then conclude and make recommendations to brands which marketing strategies to adopt [3].

Yang does research about the correctness and uniqueness of the Tiktok business model. This paper attempts to analyze the business model of chattering sound from five aspects: communication mode, user realization mode, content distribution mode, commercial mode with the purpose of researching the business model of Tiktok. The conclusion is decentralized UGC short video operating mode of chattering has its own development advantages in a long period of time, optimizing the industrial chain, and improving the content of higher quality, so as to realize the realization of better quality [4]. Ma and $\mathrm{Hu}$ did the research about the reason for success of TikTok's commercial model. They compared the business model of TikTok with other Internet companies and did a research of the position of TikTok's products, then explained how TikTok meets the need of consumers. At the same time, they also analyzed the external environment and human resources structure of TikTok. The research claimed a conclusion that TikTok shows firms from transforming economies can launch successful global products through business model innovation [5].

Zhang does research from general communication studies, sociology and psychology of the theory of resources, meaning an in-depth investigation on the short video to understand trill short construction mode, group representation of the video as well as for its prosperity than the spread of the effect and influence, to the meaning and the development of another short video practical operational Suggestions are put forward. The conclusion is that In our country, the subculture of network margin is extended under the condition of coexistence of multiple cultures. The continuous progress and transformation of technology and media forms have directly brought the flourishing landscape of TikTok [6]. Majdouline et al. studied how TikTok became a worldwide phenomenon only three years after its launch. The research studied the background of the TikTok and detailed description of the platform's business model using a Business model ontology that includes four designs: service design, organization design, technology design, and financial design. The research came to the conclusion that TikTok started providing advertisers with an increasingly reliable and sturdy platform. For now, the platform's revenue streams are generated through in-feed advertising formats, Inapp purchases, Fundraising, and Paid subscriptions. The App is putting into action multiple ways to create profit [7]. Li did the research about the internationalization history of TikTok and made a prediction of the difficulties of the internationalization of TikTok in the future. Li compared the previous International Situation of business in 2016 and 2020. Meanwhile, how did Douyin surpass its peers through technological iteration to seize the international market. Li mentioned the Moreover, he also analyzed the impact of geopolitical changes. The research claimed that TikTok catches up with the changes in international business patterns and it occupied the international market. However, the power of geopolitical changes made the internationalization of TikTok more difficult 
[8]. Xu analyzes the reasons behind TikTok popularity from marketing promotion strategy, user demand and algorithm technology. He analyzes the problems existing in the content operation and liquidation and proposes countermeasures for TikTok's further development. According to the research, the short video industry is on the rise and plays a mainstream role in the Internet industry contemporarily, and TikTok implements a variety of effective marketing strategies, precise algorithm technology and meets the needs of users. However, Xu also suggests some advice like the content homogenization appears in the TikTok, the counterfeit flooding platform, and the lack of liquidity of the platform. He recommends cultivating KOL, learns from the US "pocketing movement" and the cash reward of the volcano video to enhance TikTok application appearance [9].

Tang did a study on the new situation of marketing in the self-media Era. The research introduced the background, Characteristics and Development of SelfMedia Era. It showed the form of the TikTok market. It gave three ways to adapt to a new situation: establishing the professional team and improving content quality, Clear Positioning and Promoting Accurate Marketing, Integrating Channels and Aggregating Audience. It got a conclusion that trying to improve the connotation of short video and combining interesting entertainment with aesthetics together will be the development direction of short video in the future. At the same time, when using self-media for publicity and promotion,businesses should pay attention to online and offline integrated marketing [10].

\section{COMPETENCE WITH KWAI}

After years of development, short videos have become a part of most People's Daily lives. TikTok and One smile's fierce competition has its own advantages.

At present, TikTok adopts a defensive strategy while One smile adopts an optimized strategy. In terms of strategic development, TikTok pays more attention to promotion and innovative social networking, which makes TikTok have a higher income user than One smile and its user consumption potential is relatively greater, which is superior in the first and second-tier cities. In contrast, One smile started early, deeply plowed into the sinking market, more close to the relatively low income in the Southeast Asian market, the rural market and the third tier and lower users advantage. At present, TikTok and One smile users have a high penetration rate and the growth of domestic users is limited.

Future competition between the two sides in the market is still the key. In 2020, the market size of China's short video will reach 140.83 billion yuan which will continue to maintain a high growth trend and is expected to be close to 200 billion yuan in 2021. But TikTok's market size advantage is gradually losing to Kuaidi thanks to the growth of its social and payments businesses. Trill and quickly the first growth curve from the rapid growth of the domestic market, the current user growth dividend has gradually peaked, both are searching for a second growth curve, trill future growth comes from domestic market deeper and more liquid product internationalization. Quickly cultivates and future growth will be more from the domestic market and the development of new products.

Therefore, it doesn't believe that one smile can shake or even surpass TikTok in the future. First of all, as the product matures, the profitability of the company depends on the market it occupies and the consumer group. TikTok's consumers have stronger spending power than One smile. In the domestic market, future user growth is limited. In the overseas market, TikTok's overseas version has been effective and TikTok has started the process of monetization and realization. One smile's share of growth abroad is also relatively small, with only Brazil outgrowing TikTok's market share. Therefore, in the future, TikTok's growth abroad will only become stronger and stronger, and One smile will face more severe threats.

\section{POTENTIAL RISK}

TikTok was launched in September 2016, and it took two years to finish the breakthrough of 150 million daily activities. Achieved today's status in a very short time from an 8-person entrepreneurial team. It must not just take TikTok from the attitude of the merchandise alone, but for thorough explanations to search out such an oversized number of users reflects some common phenomena within the society. The looks of TikTok solve the most point of the present fragmentation of young people's time. On the idea of a 15-seconds-video, this point limit not only lowers the brink of creation but also takes care of the patience of the audience. The success of TikTok can't be departed from its seizing the core competitiveness of short video amalgamated with content. However, the rapid expansion brings TikTok not only a success but also some potential risks.

TikTok's content has long expanded from short videos of creative music to life, economics, business, and even politics and other diverse and all-encompassing content. In spreading into various fields, including universities to charities, this social media giant develops customized content for all walks of life. The live streaming commerce also brings TikTok an enormous advantage compared to the opposite platforms. 1) Yet be readily seen, as an enormous amount of TikTok's new entry, many first-generation users already off the stage. With the diversified topics get into TikTok, the initial users miss the start clean page full of the frilly videos made by dedicated bloggers. Some TikTok's beginning users declared that it's barely to look at a brief video post 
by a private creation but mostly are stuffed with similar content videos made by cultural communication companies, studios, various officials, and various teams. 2) The rapid development of this social media giant also involves many videos that violate relevant national laws, customs, and cultures. For instance, in China, some TikToks videos are employed by criminal groups for illegal and criminal activities like prostitution and whoring. As users upload massive amounts of videos, TikTok is consistently "deleting posts ", within the last half of 2019 alone, TikTok deleted a complete of 49 million videos worldwide, of which $1 / 4$ involved adult nudity and sexuality and other inappropriate content for youngsters. Until March 2021, users in their teens accounted for 25 percent of TikTok's active user accounts in the United States. Those with negative energy, bad taste values-oriented video widely circulated and imitation among kids under the context of the web age. Adolescence may be a golden stage that needs a decent principle and an accurate life goal concept. If it's not properly guided during this era, if there's an absence of effective supervision of the vulgar and bad videos from the media, it's used as this short video software. Teenagers, one in all TikTok's main user groups, are susceptible to adverse effects on their physical and mental state, and their physical and psychological state is worrying. Therefore, the measures taken for this phenomenon are extremely important. 3) For TikTok overseas users, their accounts have also encountered cases of political and inter-state struggles. as an example, Ethiopians and Egyptians fought one another on TikTok, and each side tried to defend their right to enter the waters of the Nile.

\section{LIVE STREAMING}

\subsection{Nature of Influencer Marketing}

Influencer marketing is very popular nowadays. Live commerce is developed on the basis of live streaming. The live streaming is a fresh way to show a product's capability to users in real-time. With more and more fans of influencers, they will try influencer marketing. When live commerce begins, influencers and followers can interact. Even the big influencer can invite superstar to the studio. Because in this way, selling goods is usually the business contact influencer so broker or distributors can't get profit margin anyway. Therefore,the price of goods sold on live commerce is often very low. In summary the nature of live commerce is a new service model of online, display and sell goods through live commerce on the internet platforms. The profit generated through live commerce has been huge. In China, one big influencer can sell 267 million (juanliu 2020) in one day through live commerce. With the expansion of the influence of live video streaming, mainstream media also joined the live commerce. This model of mainstream media plus web celebrity not only attracts stream, but also wins the heart of people. Live commerce has become one of most popular ways of shopping.

\subsection{Star Promotion}

With the expansion of TikTok's influence, more and more celebrities tend to settle in TikTok for live commerce [11]. In this way, stars change the psychological distance between fans. This is done to more simulates close contact with fans favorite stars. Fans can also interact with the stars in real-time, that they will have a better image in the fans mind. Star often brings more and more exposure, so TikTok also likes to work with them [12]. This is an effective way to increasing the number of active users and increase exposure. TikTok wants to use celebrity effect, increase user stickiness. The more user stickiness, TikTok will have more brand value [13]. Therefore, lot of celebrities active in TikTok sell merchandise through live commerce and have good achievements.

\subsection{Advantages of Live Commerce}

The difference between TikTok and Taobao is that TikTok relies more on influencer's follwer, while Taobao is more focused on power of the brand. Because of millions of followers' base, Tik Tok's influencer can sell more products, improve the conversion rate. Compared with traditional marketing methods, TikTok's live commerce can interact with customers more frequently. E-commerce can know about customer's needs in time by short video [13] — business model of TikTok. TikTok is coorperation with Alibaba. This way can easily take customers to E-commerce platform. This way turns customer's quick shopping impulses into shopping behavior. Flexible business model of TikTok. Such as influencers plus super star or set up the live commmerce in the factory, in this way the customer can feel more involved [12].

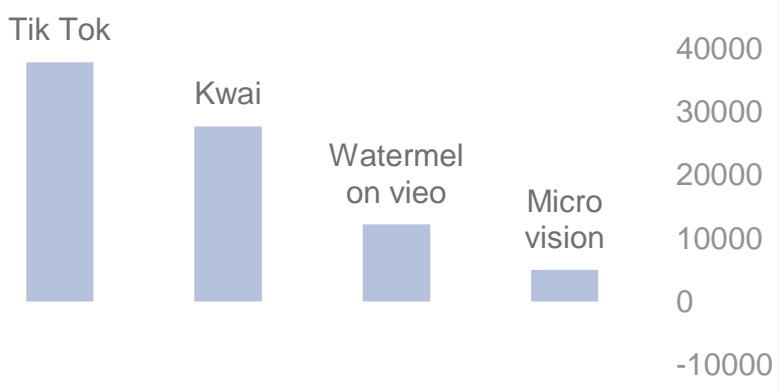

Figure 1 Numbers of short video active user [15].

In this stage, TikTok still has lot of problems. The flood of fake goods makes users difficult to protect themselves. There are more and more similar Apps appear as mobile Internet technology matured. User have lost interest of TikTok. On the other hand, As the number 
of user increases, the video level is polarization, and even some vulgar content [11].

At present, TikTok needs to make some changes. Improve the platform supervision, and report the goods of live commerce in advance. Find the users positioning. Let the users of TikTok feel the different between TikTok and other APPs. Using crash, awards and increased exposure to encourage user to participate in creation [14].

\section{REGULATION AND GLOBALIZATION}

The globalization of TikTok is deemed as successful judging by the number of overseas users. On macroscopic perspective, the expansion velocity of TikTok precedes the majority of other social networking software. 6 billion lifetime downloads TikTok has been accumulated as of December 2020 [15]. TikTok was published in 2017, in January 2021, it has 689 million monthly active users worldwide. In contrast, Instagram attained the same amount of monthly active users in the sixth year after it was published that TikTok managed to achieve in under three years, while the data of Facebook is four years [16].

In 2020, TikTok's user growth in major countries ranged from $248.7 \%$ to $20 \%$. In 2021, TikTok has become the seventh largest social app in the world [17].

On microscopic perspective, TikTok's user base is generally younger, with $47.4 \%$ of TikTok's users aged between 10 and 29 [18]. Meanwhile, statistics from other regions show that TikTok is popular among youth. In addition, TikTok's user engagement is on par with the rest of the mainstream social media market. The average user spends 52 minutes a day on TikTok. The same user community spends an average of 53 minutes a day on Instagram, compared with 49.5 minutes on Snapchat, 58.5 minutes on Facebook [19].

Therefore, it can be concluded that as a new type of social network software, TikTok achieved or surpassed other main social media on market shares and user engagement with less time cost.

However, barriers and intervention from government have been applied to the business practice of TikTok, which is divided into cultural factors and political factors. Cultural factors emerged in religious countries with high probability, TikTok is perceived as negative impact of local religion and ethics. According to the CNN report, TikTok was banned in Pakistan in October 2020 and March 2021. Islamabad claimed that "immoral and indecent content" was found in TikTok and it was believed with lacked action on cracking down specific content [20]. However, relative to the cultural factor, political factor was further concerned by administration. In 2020, the nationalism of India was stimulated by the conflict between Indian army and Chinese PLA in Galvan River Valle. Public appeal for a boycott of Chinese products and services. In June 2020, TikTok was banned by the Indian administration. According to the analysis from Sensor tower, before the ban, TikTok downloads surpassed 1.5 billion in December 2019 [21].

In addition, the political factor may lead to trade barriers or acquisition in the long run. The international progress of TikTok was considered by the supreme leader of countries and regions. Administrative Innerving and preemption were enacted and intervened in certain countries with the reason of cyberspace security or information disclosure. In 2020, TikTok was requested to sell the overseas business to an American corporation or it will be banned in America. TikTok has made an effort to stripping the relationship between itself and its Chinese parent company: the Byte dance. The database of TikTok was established in locally, the decrease of Shareholding ratio of its parent company, and the increasing in the local staff can be regarded as the accelerated progress of the indigenization of TikTok. However, the American government was pressing TikTok to sell its business and the Core Recommendation Algorithm until the anti-selling trade secret legislation was enacted by Beijing. Therefore, in the current environment of increasingly fierce global political confrontation, commercial operations may be politicized and become a manner for the government to crack down on the development of multinational enterprises in the local market.

The rapid expansion of TikTok was not only results from the high technological content of its products, which catered to the needs of users and filled the gap in the industry, but also due to the favorable external business environment. However, the cultural and political barriers to globalization that TikTok is facing are increasing in the context of the pandemic of covid 19 and the conservatism of the world.

\section{VALUATION}

Looking back at the history of ByteDance funding and valuation, it can see that valuations have changed dramatically in 2014-2016, 2017-2018, 2020-2021 
Table 1 Funding and valuation of ByteDance

\begin{tabular}{|c|c|c|c|c|c|}
\hline $\begin{array}{l}\text { Investment } \\
\text { Type }\end{array}$ & Funding Date & $\begin{array}{l}\text { Funding } \\
\text { Amount } \\
\text { ( USD ) }\end{array}$ & $\begin{array}{l}\text { Valuation } \\
\text { (billion) }\end{array}$ & $\begin{array}{c}\text { Valuation Growth } \\
\text { Rate }\end{array}$ & Lead Investors \\
\hline Series A & 2012 & $5 \mathrm{M}$ & 0.06 & - & SIG China \\
\hline Series B & 2013 & $10 \mathrm{M}$ & - & - & DST Global \\
\hline Series C & 2014 & $100 \mathrm{M}$ & 0.5 & - & Sequoia Capital China \\
\hline Series D & 2016 & $1 \mathrm{~B}$ & 11 & $2100 \%$ & Sequoia Capital China, CCB International \\
\hline Series E & 2017 & $2 \mathrm{~B}$ & 20 & $81.82 \%$ & General Atlantic \\
\hline \multirow[t]{3}{*}{ Pre-IPO } & 2018 & $3 \mathrm{~B}$ & 75 & $275.00 \%$ & $\begin{array}{c}\text { SoftBank,KKR,Primavera Capital Group, } \\
\text { General Atlantic }\end{array}$ \\
\hline & 2020 & - & 100 & $33.33 \%$ & Tiger Global Management \\
\hline & 2021 & - & 400 & $300.00 \%$ & \\
\hline
\end{tabular}

In 2014-2016, through the large domestic market capacity and demographic dividend to achieve largescale growth, ByteDance referenced domestic experiences to help TOUTIAO enter into the United States and Brazil market. In 2016, ByteDance invested in Indonesia's most popular news recommendation system $\mathrm{BABE}$ so that the smooth process of internationalization could boost its valuation; In 2017-18, the DAU broke 250 million, the MAU broke 500 million, the stay time of TOUTIAO in 2017 exceeded Tencent News, and TOUTIAO's growth rate overrun WANGYI, SOHU, SINA and Tencent. Those factors have brought more revenue to ByteDance, which may be part of the reason for its valuation increase; In 2020-21, as ByteDance's leading position among global technology was consolidated, the head effect may have led investors to raise valuations. The rising market value of TikTok, combined with other factors, has pushed up the valuation of its parent company's ByteDance. The ByteDance increased from an initial $\$ 60$ million in 2012 to $\$ 400$ billion today, an increase of 6,666.67 times. This paper analyzes whether it meets such a high valuation. In that ByteDance and BAIDU belong to the Internet industry as well as TikTok and other video software are also moving towards " daily search engine to solve people's problems ", the two will be compared in the below analysis.

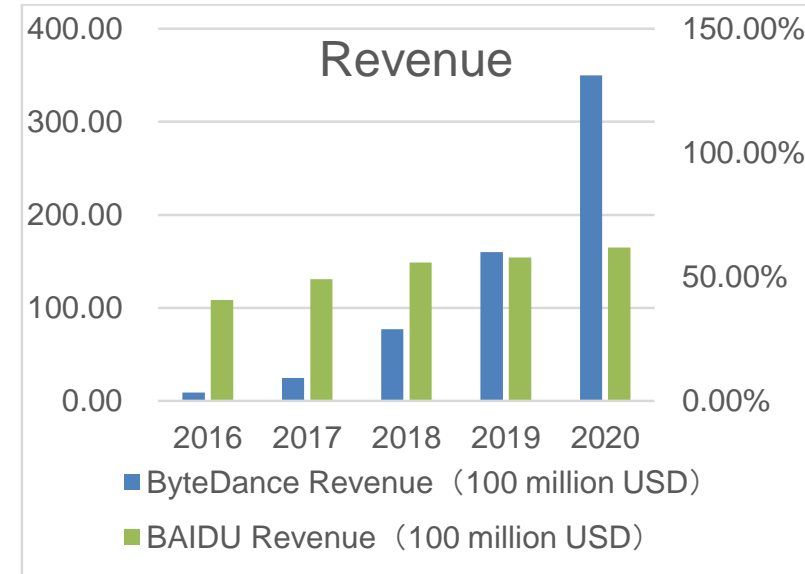

Figure 2 Revenue between ByteDance and BAIDU

\section{Growth Rate}
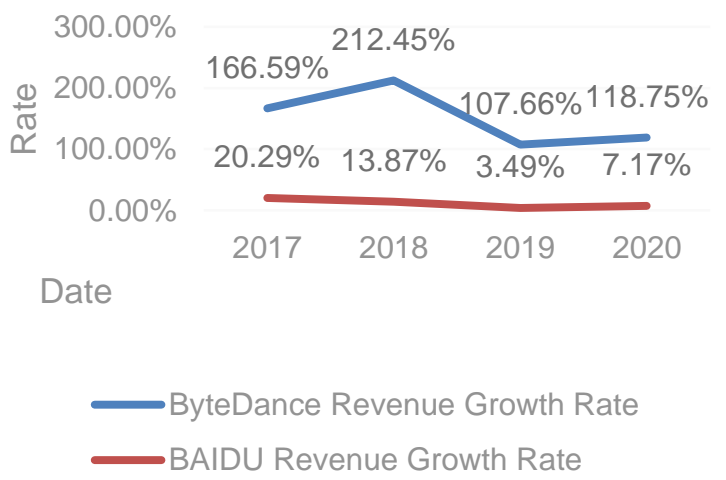

Figure 3 Growth Rate between ByteDance and BAIDU 
As can be seen from Figure 1 and Figure 2, in 2018, the revenue of ByteDance outstripped the revenue of BAIDU and its growth rate was significantly higher than BAIDU. Moreover, BAIDU's market value is currently about $\$ 75.9$ billion. Since its fast-growing operating income can bring huge net profit growth space, ByteDance's current valuation of $\$ 400$ billion is reasonable. In addition, ByteDance's sales revenue and profit margin are relatively stable and belongs to the high-income growth of the company. From the market rate point of view, because KUAISHOU' market rate is 15.71 and the revenue of ByteDance is $\$ 35$ billion, its valuation of $\$ 400$ billion is appropriate.

The valuation of ByteDance is partly affected by the valuation of TikTok. As a popular short video APP, its valuation has naturally received widespread attention. Since both TikTok and KUAISHOU' main businesses are mainly live streaming and online marketing services, I value them using relative valuation methods based on KUAISHOU. Given that KUAISHOU's 2020 financial statements show negative earnings, the price-to-earnings ratio method cannot be used and the user number price method is utilized. In 2020, data showed that KUAISHOU has 300 million daily active users. Because the current market value is also affected by macroenvironmental factors, this paper uses the market value -178.8 billion U.S. dollars to calculate the value of TikTok. Through the 600 million active daily users of TikTok, the valuation of TikTok - 357.6 billion U.S. dollars was gained.

\section{CONCLUSION}

Contemporarily, the short video industry is developing rapidly and plays a dominant role in the Internet industry. The purpose of this study was to analyze TikTok business model, engage in its product internationalization a nd valuation, and investigate the potential risk TikTok may face. Consequently, in terms of strategic development, TikTok pays more attention to promotion and innovative social networking, which makes TikTok have a higher income user than One smile, and its user consumption potential is relatively greater which is superior in the first and second-tier cities. The live streaming commerce also brings TikTok an enormous advantage compared to the opposite platforms. TikTok has taken steps to paint itself as an American brand even if the executive orders also underline what's at stake in the potential "decoupling" of the U.S.

\section{REFERENCES}

[1] Su, Y., Baker, B. J., Doyle, J. P. , \& Yan, M. . (2020)Fan engagement in fifteen seconds: Athletes' relationship marketing during a pandemic via TikTok. International Journal of Sport Communication。
[2] Bahiyah Omar, Wang Dequan(2020)Watch,Share or Create: The Influence of Personality Traits and User Motivation on TikTok Mobile Video Usage. International Association of Online Engineering.

[3] Jessie Boxin Mou(2020)Study on Social Media Marketing Campaign Strategy - TikTok and Instagram.

[4] Yang XinYuan(2018)Study on the business model of chattering abstract.Academic journal of business administration.

[5] Ma, Y., \& Hu, Y. (2021)Management and Organization Review Article contents Abstract INTRODUCTION BYTEDANCE AND TIKTOK KEY ELEMENTS OF TIKTOK'S BUSINESS CONCLUSION Footnotes References Business Model Innovation and Experimentation in Transforming Economies: ByteDance and TikTok. Retrieved 10 April 2021.

[6] Zhang Yang Yun(2018)Take TikTok as an example to research the development status and future.The home of the drama.

[7]Majdouline Mhalla, Jiang Yun, Alireza Nasiri Video-Sharing Apps Business Models: TikTok Case Study

[8] Li Xu(2019)Research on the causes of the "Tik Tok"APP Becoming popular and the Existing Problems Journal of advanced. Management Science.

[9] Shu Hui He(2020) Analyze the business operation model and development trend of TIK TOK.Economic Outlook the Bohaisea.

[10] Dihua,Tang The New Situation of Marketing in the Self-Media Era_— Taking TikTok as an Example

[11] Xu Li(2019) Research on the causes of the "TikTok"APP Becoming popular and the Existing Problems Journal of advanced.Management Science.

[12] Juan Liu(2020)Explore the model of live commerce with goods under the network short video economy.Modern Marketing.

[13] Ying Jia Hu(2020) Research on the commercial value of TikTok in china.Academic journal of Business\&Management.

[14] Shu Hui He(2020)Analyze the business operation model and development trend of TikTok.Economic Outlook the Bohaisea.

[15] Information from https://www.businessofapps.com/data/tik-tokstatistics/\#1 
[16] Information from https://www.emarketer.com/content/tiktoks-userbase-will-increase-by-triple-digit-percentagessome-countries

[17] Information from https://www.forbes.com/sites/bernardmarr/2018/12 /05/ai-in-china-how-buzzfeed-rival-bytedanceuses-machine-learning-to-revolutionize-thenews/?sh=1d9e4cce40db

[18] Information from https://datareportal.com/reports/digital-2021global-overview-report

[19] Information from https://walkthechat.com/douyinbecame-chinas-top-short-video-app-500-days/

[20] Information from https://edition.cnn.com/2021/03/12/tech/tiktokpakistan-ban-intl-hnk/index.html

[21] Information from https://edition.cnn.com/2020/08/13/tech/tiktokban-trump-india/index.html

[22] Information from https://sensortower.com/blog/tiktok-downloads-15-billion

[23] Kgn. vopp. 740-741, August 1987 [Digests 9th Annual f. Magnetics Japan, p. 301, 1982]. 